\title{
Closed Doors: Predictors of Stress, Anxiety, Depression, and PTSD During the Onset of COVID-19 Pandemic in Brazil
}

\author{
Vitor Crestani Calegaro, $\mathrm{MD}, \mathrm{PhD}^{1,2,3}$ \\ Luis Francisco Ramos-Lima, MD, $\mathrm{PhD}^{4,5}$ \\ Mauricio Scopel Hoffmann, MD, PhD ${ }^{1,5,6,7}$ \\ Gustavo Zoratto ${ }^{8}$ \\ Natália Kerber ${ }^{8}$ \\ Fernanda Coloniese Dala Costa ${ }^{8}$ \\ Vitor Daniel Picinin ${ }^{8}$ \\ Julia Köchler ${ }^{8}$ \\ Leonardo Rodrigues ${ }^{8}$ \\ Luisa Maciel ${ }^{8}$ \\ Luiza Elizabete Braun ${ }^{8}$ \\ Fernando Leite Girardi ${ }^{8}$ \\ Gabriel Olerich Cecatto ${ }^{8}$ \\ Leopoldo Pompeo Weber ${ }^{8}$ \\ Bruna Fragoso Rodrigues ${ }^{9}$
}

Alessandra Naimaier Bertolazi, MD, MSc ${ }^{1,3,4}$

Juliana Motta de Oliveira, MSc ${ }^{10}$

Bianca Lorenzi Negretto, $\mathrm{MD}^{11}$

Andrea Feijó de Mello, MD, $\mathrm{PhD}^{12}$

${ }^{1}$ Department of Neuropsychiatry, Federal University of Santa Maria, Santa Maria, Brazil.

${ }^{2}$ Educational Actions Coordination, Federal University of Santa Maria, Santa Maria, Brazil.

${ }^{3}$ University Hospital of Santa Maria, Santa Maria, Brazil.

${ }^{4}$ Post-graduate Program in Psychiatry and Behavioral Sciences, Federal University of

Rio Grande do Sul, Porto Alegre, Brazil.

${ }^{5}$ Hospital de Clínicas de Porto Alegre, Porto Alegre, Brazil. 
${ }^{6}$ National Institute of Developmental Psychiatry for Children and Adolescents (INCT-CNPq), São Paulo, Brazil.

${ }^{7}$ Care Policy and Evaluation Centre, London School of Economics and Political Science, London, United Kingdom.

${ }^{8}$ Course of Medicine, Federal University of Santa Maria, Santa Maria, Brazil.

${ }^{9}$ Multi-professional Residency, Federal University of Santa Maria, Santa Maria, Brazil.

${ }^{10}$ Post-graduation Program of Communication, Federal University of Santa Maria, Santa Maria, Brazil.

${ }^{11}$ Santa Catarina Institute of Psychiatry, São José, Brazil

${ }^{12}$ Affiliate Professor of the Department of Psychiatry, Federal University of São Paulo, São Paulo, Brazil.

Corresponding author:

Vitor Crestani Calegaro

Address: Av. Roraima, 1000 - Departamento de Neuropsiquiatria, prédio 26 -

Universidade Federal de Santa Maria. Santa Maria, Rio Grande do Sul, Brasil

Zip-code: $97105-900$

Phone: +55 5532208148

E-mail: vitor.calegaro@ufsm.br

Conflicts of Interest: Vitor Crestani Calegaro worked as speaker for Libbs Pharmaceuticals. Other authors declare no conflict of interests.

Contributions:

Vitor Crestani Calegaro: Conceptualization, methodology, formal analysis, investigation, data curation, manuscript draft, supervision $\&$ project administration. Alessandra Naimaier Bertolazi - Writing - Original Draft Andrea Feijó de Mello - Writing - Review \& Editing Bianca Lorenzi Negretto: Investigation, Writing - Original Draft \& Project Administration. 
Bruna Fragoso Rodrigues: Writing - Original Draft

Fernanda Coloniese Dala Costa: Writing - Original Draft

Fernando Leite Girardi: Writing - Original Draft

Gabriel Olerich Cecatto- Original Dfraft

Gustavo Zoratto - Formal analysis, Writing - Original Draft

Julia Köchler: Writing - Original Draft

Juliana Motta de Oliveira - Writing - Original Draft

Leonardo Rodrigues: Writing - Original Draft

Leopoldo Pompeo Weber: Writing - Original Draft

Luís Francisco Ramos-Lima: Formal analysis, Writing - Original Draft

Luisa Maciel - Writing - Original Draft

Luiza Elizabete Braun: Writing - Original Draft

Maurício S. Hoffmann: Writing - Review \& Editing.

Natália Kerber: Writing - Original Draft

Vitor Piccinin: Writing - Original Draft

\section{Highlights:}

- Distress triggered by news was the main predictor of psychological symptoms

- Sleeping problems were strong indicators of mental health problems

- People with ongoing psychiatric disorders are especially vulnerable

- Measures to prevent interpersonal trauma and financial loss are crucial

- Young people may experience great suffering at the onset of the pandemic 


\section{Abstract}

Background: The rise of mental health problems in the population directly or indirectly by the COVID-19 pandemic is a major concern. The aim of this study was to investigate and compare independent predictors of symptoms of stress, anxiety, depression, and post-traumatic stress disorder (PTSD) in Brazilians, one month after the implementation of measures of social distancing. Methods: It was a crosssectional study, performed through a web-based survey. Depression, Anxiety, and Stress Scale (DASS-21) and PTSD Checklist for DSM-5 (PCL-5) were the outcomes. Data were gathered regarding demographics, social distancing, economic problems, exposure to the news of the pandemic, psychiatric history, sleep disturbances, traumatic situations, and substance use. The Alcohol Use Disorders Identification Test - Consumption (AUDIT-C) was also included. Predictors of symptoms were investigated through hierarchical multiple linear regression. Result: Of a sample of 3,587 participants, approximately two-thirds considered that their mental health worsened after the beginning of the social restriction measures. The most important predictors of the symptoms investigated were the intensity of the distress related to pandemic news, younger age, current psychiatric diagnosis, trouble sleeping, emotional abuse or violence, and economic problems. Limitations: The convenience sample assessed online may have limited external validity. It does not represent the northern regions of the country and most participants was white wealthier females. Conclusions: These results confirm the hypothesis that a pandemic would have important impacts on the mental health of the population and indicate the level of distress related to the media as an important predictor of psychological suffering.

Keywords: Stress disorders, post-traumatic; depression; anxiety; pandemic; COVID19. 
medRxiv preprint doi: https://doi.org/10.1101/2021.08.18.21262061; this version posted August 24, 2021. The copyright holder for this preprint

\section{Introduction}

The emergence and rapid spread of COVID-19 with the potential to cause death in elder, adults, and even children, and substantial socioeconomic disruption, prompted health authorities to call for rapid measures (Holmes et al., 2020)(Kadir, 2020). Highly contagious infectious diseases, such as coronavirus disease 2019 (COVID-19), result in psychological distress to the population directly or indirectly affected. Stress may raise concomitantly with the expansion of the outbreak, which can trigger anxiety, depressive, and post-traumatic stress symptoms, especially when individuals experience the possibility of death - either in themselves or in loved ones (Sun et al., 2020). In addition, social restriction measures imposed during pandemic may result in several negative consequences to the mental health, producing stress overload. High rates of symptoms of stress, anxiety, depression, and post-traumatic stress disorder have been reported in the general population of low, middle, and highincome countries during pandemic (Xiong et al., 2020). All are affected, in a small or large extent, in a way to a possible second pandemic: of mental disorders (Choi et al., 2020).

The world population is facing new cultural and social rules, such as the regular use of facemasks and physical distancing. Mass quarantine was adopted worldwide in several contexts. Quarantine is conceptualized as the separation and restriction of movement in people who were exposed to a contagious disease to see if they become sick, aiming to reduce the risk of infecting others (CDC, 2019). Duration of quarantine, fear of infection, frustration, boredom, inadequate supplies and information along with feelings of helplessness and the loss of a sense of safety, security and financial stability evokes an increasingly familiar shudder of mistrust of others, avoidance, and withdrawal from everyday activities (Brooks et al., 2020). Social distancing associated with quarantine can be the catalyst for many mental health issues, even in previously healthy people (Usher et al., 2020).

Despite of the necessary measures to contain the rapid spread of the contagion, governmental focus has been fighting against infection, but the raising of mental disorders are often neglected (Ornell et al., 2020). In Brazil, the pre-pandemic prevalence of mental disorders was $50 \%$ higher than the global prevalence and, specifically for substance use and anxiety disorders, the prevalence was twice as high (Global Burden of Disease Collaborative Network, 2019). This continental country 
has the sixth higher population of the world, characterized by cultural heterogeneity and socioeconomical inequity. Like other low and middle-income countries, with low coverage of mental health care, the raise of mental disorders and lack of treatment may achieve epidemic proportions. Since posttraumatic stress disorder (PTSD), major depression and anxiety disorders have the potential to grow during pandemic, monitoring the mental health in the population is imperative to plan actions on prevention, health promotion, and treatment.

In this context, we developed the COVIDPsiq study (www.covidpsiq.org) to monitor the evolution of stress, depression, anxiety, and PTSD symptoms in Brazilians during the pandemic (www.covidpsiq.org). This article reports the main results of the first wave of COVIDPsiq study, which happened one month after the implementation of contagion measures by the Brazilian government. The aim of this study was to investigate and compare the independent effects of demographics, health-related anxiety, social distancing, exposure to the news of coronavirus pandemic, substance use, and traumatic situations on stress, anxiety, depression, and PTSD symptoms.

\section{Methods}

\subsection{Study design}

This is a cross-sectional study nested to a prospective cohort developed to enroll participants within nine months of follow-up during the COVID-19 outbreak, using a non-probabilistic, convenience sample. A complete description of the methodology of the longitudinal study is available elsewhere (Crestani Calegaro et al., 2020).

\subsection{Participants and context}


The inclusion criteria were to live in Brazil with 18 years or over. Participants with inconsistent answers and/or incomplete demographic questionnaire (minimal information) were excluded.

The COVIDPsiq study has begun collecting data from April $22^{\text {nd }}$ to May $8^{\text {th }}$, two months after the confirmation of the first case in São Paulo (February 26 ${ }^{\text {th }}, 2020$ ), and 41 days after the Brazilian Health Ministry had declared community transmission (March $11^{\text {th }}, 2020$ ). At the end of this phase, Brazil had summed 145,328 cases and 9,897 deaths (Ministério da Saúde, 2020). Within the south region, where most of participants was located, the spread of contagion was still centered in metropolitan areas. Since the main portion of the sample was from the state of Rio Grande do Sul, we describe some measures adopted prior to the survey. In march $16^{\text {th }}$, public calamity was declared, and the first restrictions were implemented, for example: prohibition of interstate collective transportation, activities in shopping centers, beaches, and big events (Rio Grande Do Sul, 2020a). In April $1^{\text {st }}$, more restrict measures were adopted, prohibiting the operation of schools, universities and most commercial establishments, except essential services as drug stores, grocery stores, gas stations, and other (Rio Grande Do Sul, 2020b).

\subsection{Measures}

The study protocol included demographics, occupational status (including health professional and contact with public attendance), income and unemployment, infection by SARS-COV-2, COVID-19 in relatives and close people, information about emotional and sexual abuse, physical violence, psychiatric history, frequency, and intensity of exposure to news related to the pandemic, social distancing and isolation, and substance use. The Alcohol Use Disorders Identification Test Consumption (AUDIT-C), was applied to measure the level of alcohol abuse. It is a three-item test derived from the complete assessment (AUDIT), particularly useful to identify heavy drinkers (Taufick et al., 2014). A score of 6-7 indicate high risk of dependence, and 8 or more, severe.

Two self-report instruments were used as main outcomes. The Depression, Anxiety and Stress Scale (DASS-21) is a 21-item Likert four point scale (0, 1, 2 and 
3) that measures symptom severity of these three domains (Vignola and Tucci, 2014).

DASS-21 is derived from the concept that stress is implicated in depression and anxiety, being a common component in both. Depressive symptoms are assessed as mild when the score on the items corresponding to depression is 10-13, moderate when 14-20, severe when 21-27 and extremely severe if greater than 27. Anxious symptoms are assessed as mild when the score in items corresponding to anxiety are 8-9, moderate when 10-14, severe when 15-19 and extremely severe if greater than 20. Stress symptoms are assessed as mild when the score on the corresponding items is $15-18$, moderate when $19-25$, severe when $26-33$ and extremely severe if greater than 34 (Vignola and Tucci, 2014) .The PTSD Checklist for DSM-5 (PCL-5) is a 20item questionnaire widely used for screening and monitoring the severity of symptoms over time (Lima et al., 2016). A score of 38, out of a maximum of 80 , is associated with the probable PTSD (Blevins et al., 2015).

\subsection{Procedures}

Data was gathered through a web-based survey using the SurveyMonkey® virtual platform. The engagement of participants was spontaneous, accounting with a snow-ball technique. Research disclosure included social media networks (Facebook $\AA$, Instagram ${ }^{\circledR}$, Twitter ${ }^{\circledR}$ and LinkedIn ${ }^{\circledR}$ ), corporative mailing list (emails sent by higher education institutions, governmental departments, and professional councils), digital and press media, cast news on radio and television, and through the most popular message applications in Brazil (WhatsApp ${ }^{\circledR}$ and Messenger ${ }^{\circledR}$ ). The advertisements stated that the survey was anonymous, and participants had to give consent to take part in the study. The choice of an electronic survey was based on the possibility to reach more participants while respecting social isolation restrictions in Brazil.

\subsection{Data analysis}

The data has been stored on the SurveyMonkey® server, with access through the principal investigator's (PI) account (VC). The database was anonymized and 
deidentified and can be accessed by request to the PI (VC). Data treatment and preparation (such as verification of normality and analysis of missing values) were performed. Continuous variables (age, AUDIT-C, DASS-21, and PCL-5) were not normally distributed; then, Mann-Whitney and Kruskal-Wallis (followed by pairwise comparisons) were preferred for bivariate tests, as well as Spearman's correlations.

Multivariate analyses were performed through hierarchical multiple linear regression models (HMLR) to estimate the contribution of each block of independent variables on the outcomes (DASS-21 stress, anxiety and depression, and PCL-5 scores). For each dependent variable, we built five models, from low to high complexity, adding blocks of related variables, and testing prediction improvement (Kline, 2016). All blocks included variables using forced entry, as follows: 1) controlling variables (age, sex and education); 2) socioeconomic data; 3) variables related with the pandemic (social distancing, traumatic situations, symptoms of COVID-19, clinical comorbidities, and distress related to the pandemic news); 4) psychiatric information, treatment, and sleep quality; and 5) use of substances (alcohol, tobacco, and use of anxiolytics, opioids, cannabis, and stimulant drugs at least once a month). No substantial multicollinearity was identified, and residuals were normally distributed. Outliers were excluded from the analysis. A significance level of 5\% was considered for all statistical tests. Statistical analyses were performed using SPSS@ v23. Missingness were treated by pairwise and listwise methods in bivariate and multivariate analyses, respectively.

\subsection{Ethical considerations}

The study was approved by the National Research Ethics Committee (CONEP; CAAE: 30420620.5.0000.5346). All participants were voluntary and agreed with the Informed Consent Term. Contact information for mental health care available at the Brazilian Unified Health System (SUS) was provided at the end of the study protocol. Participants were also encouraged to contact the researchers in case of emotional discomfort through the Support to the Participant Service (SPS), available in the research website (www.covidpsiq.org/SAP). The SPS provided medical and psychological teleattendance by email and video calls, using psychoeducation and 
guidance to help participants to cope with stress and referring those with clinically relevant symptoms to mental health services.

\section{Results}

During the first wave of this study (T0), 3,796 answers were achieved. Of them, 164 entries were excluded due to duplicity or missing demographics. Brazilians who were abroad during the study period were excluded from the analysis (38). Seven cases were also excluded due to inconsistent and contradictory answers. A total of 3,587 participants were included. The sample composition is described at Table 1. Figure 1 shows the prevalence of psychiatric diagnoses.

Distribution across the country was heterogeneous, with 3163 (88.2\%) respondents located in the southern region; 237 (6.6\%), in the southeast; $187(5,2 \%)$ in the other regions of Brazil. The city with more participants was Santa Maria $(n=$ $1327 ; 37.0 \%)$, located at the center of the State of Rio Grande do Sul ( $n=2698$; $75.2 \%)$. Of the total $(n=3587), 3132$ participants completed the DASS-21 scale, and 3007, the PCL-5 scale. Considering mild to extremely severe symptoms, the sample prevalence found was $58.4 \%$ for stress; $52.3 \%$ for anxiety; $61.2 \%$ for depression, and $24.5 \%$ for PTSD.

\section{$<$ Insert Table $1>$ \\ $<$ Insert Figure 1 >}

\subsection{Bivariate analysis}

Considering the inequity of the spread of coronavirus in Brazil, and the heterogeneity of the location of respondents, we begin by analyzing differences in the level of symptoms among regions, states, and cities. Despite of Kruskal-Wallis (K-W) test had shown significant differences in DASS-21 scales and PCL-5 among regions ( $P$-values ranging from 0.017 to 0.048 from DASS-21 stress to PCL-5), these findings 
were not supported by pairwise comparisons. Moreover, K-W did not present significant differences in the main outcomes comparing the city where most of participants were in with other microregions, metropolitan areas, or regions, neither did comparing Rio Grande do Sul with other states.

Figure 2 shows that almost two thirds of the respondents considered their mental health had worsened after the social restriction measures initiated. The perception of change in mental health was correlated with DASS-21 stress ( $r h o=-$ $0.615)$, anxiety ( $r h o=-0.531)$, depression $(r h o=-0.559)$, and PCL-5 $(r h o=-0.515)$. In other words, negative changes corresponded to high level of symptoms. All correlations were significant with $p$ values $<0.001$.

\section{$<$ Insert Figure 2 >}

Table 2 presents the results of $\mathrm{M}-\mathrm{W}$ and $\mathrm{K}-\mathrm{W}$ tests for bivariate analyses. Most variables were statistically associated with the outcomes, excepting diagnosis of COVID-19 suspected by a health professional or confirmed thru laboratory tests.

$<$ Insert Table $2>$

Continuous variables were analyzed through Spearman's correlations. Age was negatively correlated with DASS-21 Stress ( rho $=-0.333 ; p<0.001$ ), Anxiety ( $r h o=-0.273 ; p<0.001)$, Depression $(r h o=-0.330 ; p<0.001)$; and PCL-5 (rho $=-$ $0.276 ; p<0.001)$. Intensity of distress related to pandemic news was correlated with DASS-21 Stress $(r h o=0.531 ; p<0.001)$, Anxiety $(r h o=0.505 ; p<0.001)$, Depression $(r h o=0.446 ; p<0.001)$; and PCL-5 $(r h o=0.485 ; p<0.001)$. AUDIT-C was weakly correlated with DASS-21 Stress ( $r h o=0.080 ; p<0.001)$, Anxiety ( $r h o=$ 0.044; $p=0.013)$, Depression $(r h o=0.089 ; p<0.001)$; and PCL $(r h o=0.060 ; p=$ $0.001)$.

\subsection{Multivariate analysis}


Table 3 highlights the contribution of each block to explain the variance of the outcomes. In decrescent order, the block 3, which included variables related with the pandemic, was the most important. Then, block 1, composed by age, sex, and level of education, and block 4, psychiatric diagnoses, treatment, and sleep disturbances. The block 5 accounted for less than $1 \%$ of the total variance. All models were statistically significant.

\section{$<$ Insert Table $3>$}

Table 4 presents the resulting coefficients of hierarchical multiple linear regression. In block 1, age was negatively associated with the levels of stress, anxiety, depression, and PTSD. Female sex predicted all outcomes except depression, and level of education only predicted anxiety. Note that these variables had higher size effects for stress and anxiety than depression and PTSD.

On block 2, occupation was related with depressive symptoms, specifically being a student, unemployed or retiree. The last was also associated with anxiety and PTSD. Additionally, the greater the likelihood of indebtedness, greater psychological distress and the lower the household income, higher levels of anxiety, depression, and PTSD. Being a health worker did not increase the severity of symptoms at the time of this study. The same was true for ethnicity and marital status.

All the variables related more directly with the pandemic, included in block 3, were associated with the outcomes. The intensity of distress related with the pandemic news presented effect sizes 5 to 10 times greater than the frequency of exposition to information. Having a diagnosed clinical comorbidity of risk for COVID-19 increased anxiety, stress, and PTSD symptoms, whereas flu-like syndrome and COVID-related trauma were related only with increased anxiety. Emotional abuse or violence increased the severity of all symptoms, mostly depressive and post-traumatic stress. The social distancing was also associated with most outcomes, except the social distancing alone, which was not a predictor of anxious symptomatology. The symptoms of depression and PTSD were more influenced by being alone than being accompanied. The opposite has been found for stress and anxiety.

In block 4, psychiatric disorders and sleep disturbance were very important predictors of all dependent variables. Note that the current psychiatric diagnosis 
presented an effect size approximately 4 times greater than the previous psychiatric diagnosis. Also, ongoing or interrupted mental health treatment was associated with symptoms of post-traumatic stress. In addition, maintenance of treatment was associated with stress, while interruption was associated with depression. Short sleep duration and increased sleep latency were highly associated with the outcomes. The long sleep duration was more important than the short for predicting the symptoms of depression.

Finally, in block 5, the use of benzodiazepines without medical follow-up predicted all symptoms. The same was found for the level of alcohol consumption (AUDIT-C), except for anxiety. Moreover, tobacco use predicted symptoms of depression and PTSD, and cannabis, symptoms of depression.

$<$ Insert Table 4 >

\section{Discussion}

The current study presents the results of the baseline assessment of the COVIDPsiq study, through an internet-based survey applied approximately one month after the declaration of community transmission of corona virus and the implementation of measures to contain its spread. It must be interpreted considering a context in which participants were facing primarily the fear of the pandemic and the diverse consequences of the social distancing than infection, hospitalization, or loss of a close person due to COVID-19. Even though, two thirds of the participants declared worsening in their mental health condition. Despite the lack of an objective measure before the pandemic to document this change, the levels of stress, anxiety, depression, and PTSD were highly correlated with this self-perception. The main predictors of these symptoms were distress related with pandemic news, psychiatric diagnosis, lower age, sleeping problems, emotional abuse or violence, and economic problems, findings in accordance with previous reviews (Luo et al., 2020; Salari et al., 2020; Xiong et al., 2020).

The leading predictor of all outcomes was the level of distress related with the news of COVID-19. Findings indicate that subjective feelings raised by the information were more relevant than the frequency of exposure. Information and 
medRxiv preprint doi: https://doi.org/10.1101/2021.08.18.21262061; this version posted August 24, 2021. The copyright holder for this preprint

ways of communicating through technology may be pursued in order to cope with stress, as they enable maintenance of communication and social interaction, provide distraction and content, and can be a tool for education, work and information dissemination (Fineberg et al., 2018). However, excessive engagement in media and obsessive online activities may lead to severe problems, with significant risk of disordered and addictive use (Vismara et al., 2020). Excessive media exposure is an impairing repetitive behavior highly associated with distress intensity and negative outcomes. Gao et al (2020) showed an association of high media exposure with increased risk of anxiety and comorbid major depressive disorder compared with low exposure during COVID-19 outbreak in Wuhan, China (Gao et al., 2020). As referred by the World Health Organization (WHO), the infodemic phenomenon can difficult searching for trustworthy sources and leads to misinformation and information overload, which contributes to distress (World Health Organization, 2020).

We also suggest that the influence of the news on symptoms is linked to the way disasters are reported by the media. Although the coverage of this type of event is "emotional by nature, whether it focuses on the emotions of individuals directly affected by the tragic events or the collective emotions of the larger community reacting to the misfortunes of others like them" (Pantti and Wahl-Jorgensen, 2007), this aspect can be reinforced according to the used narrative strategies. The transmission of "faces, gestures, proper names, expressions of pain, images of victims (...) give a human and personal character to all catastrophes" (Amaral and Ascencio, 2015). At the same time, they cooperate to establish a public identification process with the suffering portrayed by the media. Thus, even the ones who were not directly affected by the disease imagine that they could have been victims. This is one of the pillars of the "virtual victim policy", a narrative strategy based on the combination of suffering, fear and risk, in which the audience is encouraged to think that "the event might happen to any individual, it may happen again and it could have been avoided (Vaz et al., 2013).

Another concern pointed in this study was the vulnerability of people with psychiatric diagnosis to aggravate their symptoms. At the period that data was gathered, many public mental health outpatient clinics were operating with closed doors, offering telephone guidance for those seeking care. The interruption of treatment, as shown in the results, predicted levels of symptoms of depression and PTSD. In the absence of a doctor, people may use benzodiazepines, alcohol, and other 
drugs to cope with stress, anxiety, and insomnia, leading to more depression, chronic PTSD, substance dependence, and domestic violence (Telles et al., 2020).

In this line, sleep disruption was clearly associated with the symptoms of stress, anxiety, depression, and PTSD. It may raise due to the confinement of unknown duration, and/or fear of getting infected, as well when facing traumatic situations. Beck et al. (2020) conducted a cross-sectional study with a representative sample of the general population in France, and showed an increase of $25 \%$ of trouble sleeping comparing with a prior general population survey (performed in 2017) (Beck et al., 2020). In a retrospective survey conducted in China, Li et al. (2020) found that the prevalence of insomnia significantly increased after the COVID-19 outbreak, with $13.6 \%$ of participants developing new-onset, and $12.5 \%$, worsening previous sleeping problems (Li et al., 2020). Furthermore, they also observed a significant increase of length of time in bed and total sleep time, and a decrease in sleep efficiency. Delayed bedtime and wakeup time were also noted. Studies have reported sleeping problems during pandemic more frequently among women, young adults, unemployed, people with financial problems, mental illness, media overexposure, COVID-19 related stress, increased severity of anxiety and depressive symptoms, and prolonged time in bed (Beck et al., 2020; Léger et al., 2020; Li et al., 2020). Daytime impairment and use of sleeping pills are usual consequences of trouble sleeping, increasing the potential for drug abuse and dependence (for example, alcohol or benzodiazepines). Such results are strongly consistent with those in the present study, which found that short sleep duration and increased sleep latency were among the most important predictors of stress, anxiety, depression, and PTSD, and long sleep duration predicting symptoms of depression.

Social distancing was independently associated with psychological distress, and we observed some differences among those alone comparing to those accompanied. Loneliness exerted more impact on depressive and post-traumatic stress symptoms, which can be explained by the deprivation of relationships, while to be accompanied was more relevant than to be alone regarding stress. Prati and Mancini (2021), meta-analyzed 25 recent studies on the impact of the COVID-19 pandemic on population mental health, and concluded that the psychological impact of social restrictions is small in magnitude and highly heterogeneous (Prati and Mancini, 2021). In our study, in fact social distancing played a secondary role to the explanation of the symptoms comparing the effect sizes with the main predictors, but 
the containment measures applied may had indirect effects, which were measured by other variables, i.e., economic problems and emotional abuse. For some people, staying more time with relatives or partner may flare interpersonal tension, disagreements, and, in some cases, family violence. The last refers to threats or other forms of violent behavior in families, which can be physical, sexual, psychological, or economic, in addition to child abuse and intimate partner violence. A raise in this behavior due to forced coexistence, economic stress, and fears about the corona virus has been observed in many countries (Bright et al., 2020; Campbell, 2020). In Brazil, between March $1^{\text {st }}$ to $25^{\text {th }}, 2020$, there was an $18 \%$ increase in the number of complaints of domestic violence produced by the "call 100" and "call 1808" services recorded by the National Ombudsman for Human Rights (ONDH) from the Ministry of Women, Family and Human Rights (MMFDH) (Vieira et al., 2020). According to Marques et al. (2020), during the pandemic, this type of violence is associated with an increase in the level of stress generated by the fear of falling ill, uncertainty about the future, increased consumption of alcohol and other psychoactive substances (Marques et al., 2020). Additionally, Vieira et al (2020) included economic stress, greater exposure to explorers, and reduced support options, such as contact with other relatives and friends, as risk factors (Vieira et al., 2020).

Socioeconomic factors were independently associated with many symptoms, pointing to potential sources of worries, frustration, and distress. Unemployment and financial indebtedness tend to worse during pandemics, which, in addition to low family income, can have lasting effects on people's lives. According to the Well Being Trust, it is expected an increase on deaths of despair due to alcohol, drugs, and suicide, as consequence of unemployment in the years following the outbreak of the pandemic (Peterson et al., 2020). Furthermore, our findings showed that retirees presented more symptoms of anxiety, depression, and PTSD. Independently of age, retired either due to elderly or chronic disease may deal with reduced autonomy, financial problems, free time but deprivation of usual activities, thus becoming distressed and fearing the illness and the death. Of note, students presented higher levels of depression. They represented one-third of this sample and were mostly undergraduate or postgraduate studying remotely. Accordingly, a study carried out in Jordan during the Covid-19 pandemic by Naser et al. (2020) reported a higher prevalence of anxiety among university students (21.5\%), comparing with health professionals (11.3\%) and the general population (8.8\%) (Naser et al., 2020). Before 
medRxiv preprint doi: https://doi.org/10.1101/2021.08.18.21262061; this version posted August 24, 2021. The copyright holder for this preprint

pandemic, Auerbach et al. (2016) had found an one-year prevalence of mental disorders in one-fifth of university students from 21 low to high-income countries (Auerbach et al., 2016). In this phase of life, young adults usually must cope with high academic demands, social pressure related to the future profession, and financial dependence. We hypothesize that concerns about possible impairments on practical learning, the lack of resources to access online classes, routine disruption, and the distancing from family, friends, and loved ones may raise feelings of sadness, inability, low self-esteem, abandonment, and hopelessness. In this sense, Wu et al. (2020) have shown that the effect of uncertainty stress on mental disorders were much superior than life and study stress, in a nationwide study with college students (Wu et al., 2020).

Having at least one comorbidity of risk for complications of COVID-19 predicted stress and PTSD, besides of anxiety symptoms. Additionally, flu-like syndrome and COVID-related trauma predicted symptoms of anxiety. Noteworthy, diagnosed, or suspected COVID-19 was not associated with the outcomes. Taken together, these issues suggest the fear of contagion, despite the disease itself. Note that at the time that data was gathered cases were emerging in Brazil, but most of the sample had not become infected or had lost a relative or friend. These findings can be explained by health anxiety, which may be associated with cyberchondria, and worsen with media overexposure (Jungmann and Witthöft, 2020). Health anxiety promotes preventive behaviors, such as washing hands and adhering to social distancing, but it also has a negative impact on work and family involvement (Ornell et al., 2020; Trougakos et al., 2020).

Demographics also played an important role in predicting the outcomes. The study found that the younger, the higher the levels of symptoms, with the effects of the age being more notable in stress. This group may suffer more with the distance of friends, family, loved ones, lack of social activities, job instability (Xiong et al., 2020). Although both sexes increased their psychological symptoms during the quarantine, women showed higher levels of stress, depression and anxiety (Jia et al., 2020). In agreement, other studies also found sex differences in the symptom distribution, with women reporting significantly higher levels of anxiety, depression (Solomou and Constantinidou, 2020) and PTSD (Liu et al., 2020) than men. Despite of the biological influence of sex, another hypothesis is the need to reconcile work with the care of children and domestic chores, which affects more the career 
progression and the salary of women than men. Finally, we found that low level of education was associated with symptoms of anxiety. In opposite way, the review of Salari et al. (2020), showed that higher levels of education were related to greater symptoms of stress, anxiety, and depression. The authors argued that the high level of education may lead to self-awareness of health, and therefore, to health anxiety. In Brazil, low education is linked to unemployment, poor working conditions, and low access to health services that may cause worry and anxiety.

This study must be understood considering its limitations. First, this is an internet-based survey in which convenience sample bias may limit its external validity. It does not represent northern regions of the country and, as several surveys of similar method, most participants are white wealthier females. Hence, extrapolations of the findings to other sociodemographic characteristics may not apply. Nonetheless, the sample is from an underrepresented area of the world, in a country with an important impact of the pandemic, which will be useful to compose the assessment of the global mental health outcomes of SARS-CoV-2. Second, all the pre-pandemic information was collected retrospectively. We attempt to minimize this by asking questions regarding current information, such as employment, living conditions and diagnosis, that are not likely be misled by recall bias. Third, it was not possible to evaluate if symptoms are clinically relevant to infer an increase incidence of mental illness. The symptomatic assessment utility lies on assessment of distress oscillation and comparability across the globe, using instruments validated in similar samples and widely used in other studies on the same topic.

Lastly, our current findings were able to put some light on relevant variables that, at the initial months of COVID-19 pandemic, appear to have a crucial role on symptoms of anxiety, depression, stress, and post-traumatic stress. It was shown that self-perception of suffering was highly correlated to the outcomes in study; selfreferred level of distress related with the news of pandemic was the most important predictor of mental soreness of all, what may indicate that subjective issues are a large part of what compounds mental health symptoms during traumatic exposure. We identified other external and internal variables that were shown to have association with symptoms of anxiety, depression, stress, and PTSD, as age, psychiatric diagnosis, sleeping problems, emotional abuse and violence, female gender, being a student, retiree or unemployed, low income and probability of financial loss during quarantine, as well as substance use. These findings support the importance of some 
actions that may lead to a better event-coping strategy, as maintaining the operation of public healthcare institutions, so all layers of the population can have worthy access and attendance, mostly those who are already mentally ill. To avoid the risk of contagion and, at the same time, providing mental health support, telepsychiatry and telepsychotherapy are valuable solutions that may help patients with variable levels of severity (Kalin et al., 2020; Salum et al., 2020a, 2020b). The feasibility of online interventions, however, is dependent of technological resources, as broadband internet connections, availability of appropriate smartphones or computers, as well as ability to use them. This applies for both patients and care providers, requires investment and time to implement. Nevertheless, the economic and technologic inequities must be taken into account, as they limit the access of online interventions for elder, children, people of low-income, with disabilities and with cognitive impairment (Nadkarni et al., 2020). As a public health perspective, we strongly recommend that mental health services should receive investments to implement telehealth and to adapt the setting to meet biosafety regulations, to keep face-to-face attendance for those people without digital accessibility.

Considering that self-referred level of distress related with media exposure was the most significant predictor of mental outcome, it's mandatory to considerer controlling strategies against compulsive use of technology as a matter of mental coping (Király et al., 2020). By the other hand, media can be a powerful ally to spread psychoeducational information, using many digital resources, such as videos, podcasts, and written material. They may be useful to clarify the risks of substance misuse, providing information on sleep hygiene, and encouraging people to seek appropriate treatment when necessary, indicating how to access and where to find mental health services of reference for example. Moreover, attention should be paid at specific stratum of our society, as students and those at risk of financial loss during the COVID19 pandemic; some actions as financial-security loans, flexibilization of study chronogram and active search of these individuals by mental health programs should lead to a better mental health scenario in the future.

\section{Acknowledge}


Dr. Hoffmann is supported by the research grant of the Brazilian Ministry of Health under the “Termo De Execução Descentralizada - TED 12/2019”.

\section{References}

Auerbach, R.P., Alonso, J., Axinn, W.G., Cuijpers, P., Ebert, D.D., Green, J.G., Hwang, I., Kessler, R.C., Liu, H., Mortier, P., Nock, M.K., Pinder-Amaker, S., Sampson, N.A., Aguilar-Gaxiola, S., Al-Hamzawi, A., Andrade, L.H., Benjet, C., Caldas-de-Almeida, J.M., Demyttenaere, K., Florescu, S., de Girolamo, G., Gureje, O., Haro, J.M., Karam, E.G., Kiejna, A., Kovess-Masfety, V., Lee, S., McGrath, J.J., O’Neill, S., Pennell, B.-E., Scott, K., ten Have, M., Torres, Y., Zaslavsky, A.M., Zarkov, Z., Bruffaerts, R., 2016. Mental disorders among college students in the World Health Organization World Mental Health Surveys. Psychol. Med. 46, 2955-2970. https://doi.org/10.1017/S0033291716001665

Beck, F., Léger, D., Fressard, L., Peretti-Watel, P., Verger, P., 2020. Covid-19 health crisis and lockdown associated with high level of sleep complaints and hypnotic uptake at the population level. J. Sleep Res. 6-11.

https://doi.org/10.1111/jsr.13119

Blevins, C.A., Weathers, F.W., Davis, M.T., Witte, T.K., Domino, J.L., 2015. The Posttraumatic Stress Disorder Checklist for DSM-5 (PCL-5): Development and Initial Psychometric Evaluation. J. Trauma. Stress 28, 489-498.

https://doi.org/10.1002/jts.22059

Bright, C.F., Burton, C., Kosky, M., 2020. Considerations of the impacts of COVID19 on domestic violence in the United States. Soc. Sci. Humanit. Open 2, 100069. https://doi.org/10.1016/j.ssaho.2020.100069

Brooks, S.K., Webster, R.K., Smith, L.E., Woodland, L., Wessely, S., Greenberg, N., Rubin, G.J., 2020. The psychological impact of quarantine and how to reduce it: rapid review of the evidence. Lancet 395, 912-920. https://doi.org/10.1016/S0140-6736(20)30460-8

Campbell, A.M., 2020. An increasing risk of family violence during the Covid-19 pandemic: Strengthening community collaborations to save lives. Forensic Sci. Int. Reports 2, 100089. https://doi.org/10.1016/j.fsir.2020.100089 
CDC, 2019. COVID-19: When to Quarantine | CDC [WWW Document]. Coronavirus Dis. 2019. URL https://www.cdc.gov/coronavirus/2019-ncov/if-you-aresick/quarantine.html (accessed 1.26.21).

Choi, K.R., Heilemann, M.S. V., Fauer, A., Mead, M., 2020. A Second Pandemic: Mental Health Spillover From the Novel Coronavirus (COVID-19). J. Am. Psychiatr. Nurses Assoc. 26, 340-343. https://doi.org/10.1177/1078390320919803

Crestani Calegaro, V., Lorenzi Negretto, B., Pompeo Weber, L., Kerber, N., Zoratto, G., Rodrigues, L., Elizabete Braun, L., Kochler, J., Leite Girardi, F., Daniel Picinin, V., Maciel, L., Salomão Labre, G., Coloniese Dala Costa, F., 2020. Monitoring the evolution of posttraumatic symptomatology, depression and anxiety during the COVID-19 pandemic in Brazilians (COVIDPsiq), PREPRINT (Version 2) avalilable at Research Square. https://doi.org/10.21203/rs.3.pex945/v2

Fineberg, N.A., Demetrovics, Z., Stein, D.J., Ioannidis, K., Potenza, M.N., Grünblatt, E., Brand, M., Billieux, J., Carmi, L., King, D.L., Grant, J.E., Yücel, M., Dell’Osso, B., Rumpf, H.J., Hall, N., Hollander, E., Goudriaan, A., Menchon, J., Zohar, J., Burkauskas, J., Martinotti, G., Van Ameringen, M., Corazza, O., Pallanti, S., Chamberlain, S.R., 2018. Manifesto for a European research network into Problematic Usage of the Internet. Eur. Neuropsychopharmacol. 28, 1232-1246. https://doi.org/10.1016/j.euroneuro.2018.08.004

Franz Amaral, M., Lozano Ascencio, C., 2015. Palavras que dão a volta ao mundo: a personalização das catástrofes na mídia. Chasqui. Rev. Latinoam. Comun. 0, 243-258.

Gao, J., Zheng, P., Jia, Y., Chen, H., Mao, Y., Chen, S., Wang, Y., Fu, H., Dai, J., 2020. Mental health problems and social media exposure during COVID-19 outbreak. PLoS One 15, 1-10. https://doi.org/10.1371/journal.pone.0231924

Global Burden of Disease Collaborative Network, 2019. Global Burden of Disease Collaborative Network. Global Burden of Disease Study 2019 (GBD 2019) Results., Seattle, United States: Institute for Health Metrics and Evaluation (IHME).

Holmes, E.A., O’Connor, R.C., Perry, V.H., Tracey, I., Wessely, S., Arseneault, L., Ballard, C., Christensen, H., Cohen Silver, R., Everall, I., Ford, T., John, A., Kabir, T., King, K., Madan, I., Michie, S., Przybylski, A.K., Shafran, R., 
Sweeney, A., Worthman, C.M., Yardley, L., Cowan, K., Cope, C., Hotopf, M., Bullmore, E., 2020. Multidisciplinary research priorities for the COVID-19 pandemic: a call for action for mental health science. The Lancet Psychiatry 0366, 1-14. https://doi.org/10.1016/S2215-0366(20)30168-1

Jia, R., Ayling, K., Chalder, T., Massey, A., Broadbent, E., Coupland, C., Vedhara, K., 2020. Mental health in the UK during the COVID-19 pandemic: crosssectional analyses from a community cohort study. BMJ Open 10, e040620. https://doi.org/10.1136/bmjopen-2020-040620

Jungmann, S.M., Witthöft, M., 2020. Health anxiety, cyberchondria, and coping in the current COVID-19 pandemic: Which factors are related to coronavirus anxiety? J. Anxiety Disord. 73, 102239. https://doi.org/10.1016/j.janxdis.2020.102239

Kadir, M.A., 2020. Role of telemedicine in healthcare during COVID-19 pandemic in developing countries. Telehealth Med. Today. https://doi.org/10.30953/tmt.v5.187

Kalin, M.L., Garlow, S.J., Thertus, K., Peterson, M.J., 2020. Rapid Implementation of Telehealth in Hospital Psychiatry in Response to COVID-19. Am. J. Psychiatry 177, 636-637. https://doi.org/10.1176/appi.ajp.2020.20040372

Király, O., Potenza, M.N., Stein, D.J., King, D.L., Hodgins, D.C., Saunders, J.B., Griffiths, M.D., Gjoneska, B., Billieux, J., Brand, M., Abbott, M.W., Chamberlain, S.R., Corazza, O., Burkauskas, J., Sales, C.M.D., Montag, C., Lochner, C., Grünblatt, E., Wegmann, E., Martinotti, G., Lee, H.K., Rumpf, H.J., Castro-Calvo, J., Rahimi-Movaghar, A., Higuchi, S., Menchon, J.M., Zohar, J., Pellegrini, L., Walitza, S., Fineberg, N.A., Demetrovics, Z., 2020. Preventing problematic internet use during the COVID-19 pandemic: Consensus guidance. Compr. Psychiatry 100, 1-4. https://doi.org/10.1016/j.comppsych.2020.152180

Kline, R.B., 2016. Principles and Practice of Structural Equation Modeling: Fourth Edition, Fourth. ed. Guilford Press, New York.

Léger, D., Beck, F., Fressard, L., Verger, P., Peretti-watel, P., Group, C., 2020. Letter to the Editor Poor sleep associated with overuse of media during the COVID-19 lockdown 1-3. https://doi.org/10.1093/sleep/zsaa125

Li, Y., Qin, Q., Sun, Q., Sanford, L.D., Vgontzas, A.N., Tang, X., 2020. Insomnia and psychological reactions during the COVID-19 outbreak in China. J. Clin. sleep Med. JCSM Off. Publ. Am. Acad. Sleep Med. https://doi.org/10.5664/jcsm.8524 
Lima, E. de P., Vasconcelos, A.G., Berger, W., Kristensen, C.H., Nascimento, E. do, Figueira, I., Mendlowicz, M.V., 2016. Cross-cultural adaptation of the Posttraumatic Stress Disorder Checklist 5 (PCL-5) and Life Events Checklist 5 (LEC-5) for the Brazilian context. Trends Psychiatry Psychother. 38, 207-215. https://doi.org/10.1590/2237-6089-2015-0074

Liu, N., Zhang, F., Wei, C., Jia, Y., Shang, Z., Sun, L., Wu, L., Sun, Z., Zhou, Y., Wang, Y., Liu, W., 2020. Prevalence and predictors of PTSS during COVID-19 outbreak in China hardest-hit areas: Gender differences matter. Psychiatry Res. 287. https://doi.org/10.1016/j.psychres.2020.112921

Luo, M., Guo, L., Yu, M., Jiang, W., Wang, H., 2020. The psychological and mental impact of coronavirus disease 2019 (COVID-19) on medical staff and general public - A systematic review and meta-analysis. Psychiatry Res. 291, 113190. https://doi.org/10.1016/j.psychres.2020.113190

Marques, E.S., de Moraes, C.L., Hasselmann, M.H., Deslandes, S.F., Reichenheim, M.E., 2020. Violence against women, children, and adolescents during the COVID-19 pandemic: Overview, contributing factors, and mitigating measures. Cad. Saude Publica 36. https://doi.org/10.1590/0102-311X00074420

Ministério da Saúde, 2020. Coronavírus: 145.328 casos confirmados e 9.897 mortes [WWW Document]. URL https://antigo.saude.gov.br/noticias/agenciasaude/46857-coronavirus-145-328-casos-confirmados-e-9-897-mortes (accessed 4.18.21).

Nadkarni, A., Hasler, V., AhnAllen, C.G., Amonoo, H.L., Green, D.W., LevyCarrick, N.C., Mittal, L., 2020. Telehealth During COVID-19-Does Everyone Have Equal Access? Am. J. Psychiatry 177, 1093-1094. https://doi.org/10.1176/appi.ajp.2020.20060867

Naser, A.Y., Dahmash, E.Z., Al-Rousan, R., Alwafi, H., Alrawashdeh, H.M., Ghoul, I., Abidine, A., Bokhary, M.A., AL-Hadithi, H.T., Ali, D., Abuthawabeh, R., Abdelwahab, G.M., Alhartani, Y.J., Al Muhaisen, H., Dagash, A., Alyami, H.S., 2020. Mental health status of the general population, healthcare professionals, and university students during 2019 coronavirus disease outbreak in Jordan: A cross-sectional study. Brain Behav. 10, 1-13. https://doi.org/10.1002/brb3.1730

Ornell, F., Schuch, J.B., Sordi, A.O., Kessler, F., 2020. "Pandemic fear" and COVID19 $\square:$ Mental Health Burden and Strategies. Brazilian J. Psychiatry 0.

Pantti, M., Wahl-Jorgensen, K., 2007. On the political possibilities of therapy news. 
Estud. em Comun. 1, 5.

Peterson, S., Westfall, J.M., Miller, B.F., 2020. Projected Deaths of Despair During the Coronavirus Recession.

Prati, G., Mancini, A.D., 2021. The psychological impact of COVID-19 pandemic lockdowns: a review and meta-analysis of longitudinal studies and natural experiments. Psychol. Med. 51, 201-211. https://doi.org/10.1017/S0033291721000015

Rio Grande Do Sul, 2020a. DECRETO N 55.128, DE 19 DE MARÇO DE 2020.

Rio Grande Do Sul, 2020b. DECRETO N 55.154, DE $1^{\circ}$ DE ABRIL DE 2020.

Salari, N., Hosseinian-Far, A., Jalali, R., Vaisi-Raygani, A., Rasoulpoor, Shna, Mohammadi, M., Rasoulpoor, Shabnam, Khaledi-Paveh, B., 2020. Prevalence of stress, anxiety, depression among the general population during the COVID-19 pandemic: a systematic review and meta-analysis. Global. Health 16, 57. https://doi.org/10.1186/s12992-020-00589-w

Salum, G.A., Rehmenklau, J.F., Csordas, M.C., Pereira, F.P., Castan, J.U., Ferreira, A.B., Delgado, V.B., Bolzan, L. de M., de Lima, M.A., Blauth, J.H., dos Reis, J.R., Rocha, P.B., Guerra, T.A., Saraiva, I.M., Gramz, B. de C., Ronchi, B.R., Ribeiro, B.L., Konig, D.F., Grevet, E.H., de Pinho, L.B., Schneider, J.F., Eustáquio, P.R., Ramos, M.Z., Marques, M.F., Axelrud, L.K., Baeza, F.L., Lacko, S.E., 2020a. Supporting people with severe mental health conditions during the COVID-19 pandemic: considerations for low- and middle-income countries using telehealth case management. Brazilian J. Psychiatry 42, 451-452. https://doi.org/10.1590/1516-4446-2020-1078

Salum, G.A., Spanemberg, L., Hartmann de Souza, L., Harzheim, E., Teixeira, D.S., Simioni, A.R., Motta, L.S., Kristensen, C.H., de Abreu Costa, M., Pio de Almeida Fleck, M., Manfro, G.G., Dreher, C.B., Teodoro, M.D., Marques, M. das C., 2020b. Letter to the editor: Training mental health professionals to provide support in brief telepsychotherapy and telepsychiatry for health workers in the SARS-CoV-2 pandemic. J. Psychiatr. Res. https://doi.org/10.1016/j.jpsychires.2020.09.036

Solomou, I., Constantinidou, F., 2020. Prevalence and predictors of anxiety and depression symptoms during the COVID-19 pandemic and compliance with precautionary measures: Age and sex matter. Int. J. Environ. Res. Public Health 17, 1-19. https://doi.org/10.3390/ijerph17144924 
Sun, L., Sun, Z., Wu, L., Zhu, Z., Zhang, F., Shang, Z., Jia, Y., Gu, J., Zhou, Y., Wang, Y., Liu, N., Liu, W., 2020. Prevalence and Risk Factors of Acute Posttraumatic Stress Symptoms during the COVID-19 Outbreak in Wuhan, China. medRxiv 2020.03.06.20032425. https://doi.org/10.1101/2020.03.06.20032425

Taufick, M.L. de C., Evangelista, L.A., Silva, M. da, Oliveira, L.C.M. de, 2014. Alcohol consumption patterns among patients in primary health care and detection by health professionals. Cad. Saude Publica 30, 427-32. https://doi.org/10.1590/0102-311X00030813

Telles, L.E. de B., Valença, A.M., Barros, A.J.S., da Silva, A.G., 2020. Domestic violence in the COVID-19 pandemic: a forensic psychiatric perspective. Brazilian J. Psychiatry 00, 5-6. https://doi.org/10.1590/1516-4446-2020-1060

Trougakos, J.P., Chawla, N., McCarthy, J.M., 2020. Working in a pandemic: Exploring the impact of COVID-19 health anxiety on work, family, and health outcomes. J. Appl. Psychol. 105, 1234-1245. https://doi.org/10.1037/ap10000739

Usher, K., Bhullar, N., Jackson, D., 2020. Life in the pandemic: Social isolation and mental health. J. Clin. Nurs. 29, 2756-2757. https://doi.org/10.1111/jocn.15290

Vaz, P., Cardoso, J.M., Felix, C.B., 2013. Risco, sofrimento e vítima virtual: a política do medo nas narrativas jornalísticas contemporâneas. Rev. Contracampo 24-42. https://doi.org/10.22409/contracampo.v0i25.291

Vieira, P.R., Garcia, L.P., Maciel, E.L.N., 2020. The increase in domestic violence during the social isolation: What does it reveals? Rev. Bras. Epidemiol. 23. https://doi.org/10.1590/1980-549720200033

Vignola, R.C.B., Tucci, A.M., 2014. Adaptation and validation of the depression, anxiety and stress scale (DASS) to Brazilian Portuguese. J. Affect. Disord. 155, 104-109. https://doi.org/10.1016/j.jad.2013.10.031

Vismara, M., Caricasole, V., Starcevic, V., Cinosi, E., Dell’Osso, B., Martinotti, G., Fineberg, N.A., 2020. Is cyberchondria a new transdiagnostic digital compulsive syndrome? A systematic review of the evidence. Compr. Psychiatry 99, 152167. https://doi.org/10.1016/j.comppsych.2020.152167

World Health Organization, 2020. Novel Coronavirus(2019-nCoV) Situation Report 13 [WWW Document].

Wu, D., Yu, L., Yang, T., Cottrell, R., Peng, S., Guo, W., Jiang, S., 2020. The Impacts of Uncertainty Stress on Mental Disorders of Chinese College Students: 
Evidence From a Nationwide Study. Front. Psychol. 11, 1-9.

https://doi.org/10.3389/fpsyg.2020.00243

Xiong, J., Lipsitz, O., Nasri, F., Lui, L.M.W., Gill, H., Phan, L., Chen-Li, D.,

Iacobucci, M., Ho, R., Majeed, A., McIntyre, R.S., 2020. Impact of COVID-19

pandemic on mental health in the general population: A systematic review. J.

Affect. Disord. 277, 55-64. https://doi.org/10.1016/j.jad.2020.08.001 


\section{It is made available under a CC-BY-NC-ND 4.0 International license .}

Table 1. Sample characteristics.

\begin{tabular}{|c|c|c|c|}
\hline & & $\mathrm{N}$ & $\%$ \\
\hline \multirow[t]{2}{*}{ Sex } & Male & 849 & $23.7 \%$ \\
\hline & Female & 2738 & $76.3 \%$ \\
\hline Age (Median; $I Q I)$ & & 29.0 & 19.0 \\
\hline \multirow[t]{4}{*}{ Education } & Primary or secondary & 339 & $9.5 \%$ \\
\hline & Undergraduate & 1301 & $36.3 \%$ \\
\hline & Graduated & 665 & $18.5 \%$ \\
\hline & Post-graduated & 1282 & $35.7 \%$ \\
\hline \multirow[t]{2}{*}{ Ethnicity } & White & 3069 & $85.6 \%$ \\
\hline & Non-white & 518 & $14.4 \%$ \\
\hline \multirow[t]{2}{*}{ Marital status } & Single. divorced or widowed & 2274 & $63.4 \%$ \\
\hline & Married or stable relationship & 1313 & $36.6 \%$ \\
\hline \multirow[t]{3}{*}{ Living arrangement } & With family or partner & 2647 & $73.8 \%$ \\
\hline & With other people & 413 & $11.5 \%$ \\
\hline & Alone & 527 & $14.7 \%$ \\
\hline \multirow[t]{5}{*}{ Occupation } & Health worker & 653 & $18.2 \%$ \\
\hline & Worker & 1280 & $35.7 \%$ \\
\hline & Student & 1317 & $36.7 \%$ \\
\hline & Unemployed & 194 & $5.4 \%$ \\
\hline & Retired & 143 & $4.0 \%$ \\
\hline \multirow[t]{5}{*}{ Family income (minimum salaries ${ }^{\mathrm{a}}$ ) } & 1 or less & 231 & $6.4 \%$ \\
\hline & 1 to 2 & 457 & $12.7 \%$ \\
\hline & 2 to 8 & 1667 & $46.5 \%$ \\
\hline & 8 to 11 & 470 & $13.1 \%$ \\
\hline & 11 or more & 762 & $21.2 \%$ \\
\hline \multirow[t]{3}{*}{ Social distancing } & No & 463 & $14.1 \%$ \\
\hline & Yes, alone & 328 & $10.0 \%$ \\
\hline & Yes, accompanied & 2486 & $75.9 \%$ \\
\hline \multirow{4}{*}{ Financial indebtedness ${ }^{\mathrm{b}}$} & Improbable & 1226 & $37.4 \%$ \\
\hline & Possible & 1366 & $41.7 \%$ \\
\hline & Highly probable & 434 & $13.2 \%$ \\
\hline & Already in debt & 252 & $7.7 \%$ \\
\hline \multirow[t]{9}{*}{ Clinical comorbidity of risk } & Any & 989 & $29.5 \%$ \\
\hline & Diabetes mellitus & 70 & $2.1 \%$ \\
\hline & High blood pressure & 237 & $7.1 \%$ \\
\hline & Respiratory problems & 402 & $12.0 \%$ \\
\hline & HIV/AIDS & 18 & $0.5 \%$ \\
\hline & Cancer & 41 & $1.2 \%$ \\
\hline & Cardiovascular problems & 61 & $1.8 \%$ \\
\hline & Obesity & 341 & $10.2 \%$ \\
\hline & Use of immune suppressor & 76 & $2.3 \%$ \\
\hline \multirow[t]{2}{*}{ COVID-19 } & Flu-like syndrome ${ }^{\mathrm{c}}$ & 56 & $1.7 \%$ \\
\hline & Suspected or confirmed $^{\mathrm{d}}$ & 60 & $1.8 \%$ \\
\hline \multirow[t]{6}{*}{ COVID-related trauma } & Any & 200 & $6.1 \%$ \\
\hline & Living with person that had COVID-19 & 66 & $2.0 \%$ \\
\hline & Had distancing of close person due to COVID-19 & 54 & $1.6 \%$ \\
\hline & Someone close was hospitalized due to COVID-19 & 67 & $2.0 \%$ \\
\hline & Loss of relative due to COVID-19 & 17 & $0.5 \%$ \\
\hline & Loss of close person due to COVID-19 & 26 & $0.8 \%$ \\
\hline Abuse/violence after the onset of pandemic & Any & 395 & $12.8 \%$ \\
\hline & Emotional abuse & 388 & $12.6 \%$ \\
\hline & Sexual abuse & 5 & $0.2 \%$ \\
\hline & Physical violence & 28 & $0.9 \%$ \\
\hline Current psychological or psychiatric treatment & No & 2258 & $67.3 \%$ \\
\hline & Treatment maintained during pandemic & 576 & $17.2 \%$ \\
\hline & Treatment interrupted during pandemic & 523 & $15.6 \%$ \\
\hline Substance use & Tobacco & 279 & $8.3 \%$ \\
\hline & Benzodiazepines $^{\mathrm{e}}$ & 263 & $7.3 \%$ \\
\hline & Opioids $^{\mathrm{e}}$ & 131 & $3.7 \%$ \\
\hline & Cannabis $^{f}$ & 446 & $13.3 \%$ \\
\hline & Cocaine, ecstasy or $\operatorname{LSD}^{\mathrm{f}}$ & 172 & $5.1 \%$ \\
\hline Risk of alcohol dependence (AUDIT-C) & No risk/low & 1859 & $55.4 \%$ \\
\hline & Moderate & 1045 & $31.1 \%$ \\
\hline & High & 285 & $8.5 \%$ \\
\hline & Severe & 168 & $5.0 \%$ \\
\hline Stress (DASS-21) & Normal & 1302 & $41.6 \%$ \\
\hline & Mild & 406 & $13.0 \%$ \\
\hline & Moderate & 553 & $17.7 \%$ \\
\hline & Severe & 531 & $17.0 \%$ \\
\hline & Extremely severe & 340 & $10.9 \%$ \\
\hline
\end{tabular}


medRxiv preprint doi: https://doi.org/10.1101/2021.08.18.21262061; this version posted August 24, 2021. The copyright holder for this preprint (which was not certified by peer review) is the author/funder, who has granted medRxiv a license to display the preprint in perpetuity.

\section{It is made available under a CC-BY-NC-ND 4.0 International license.}

Anxiety (DASS-21)

Depression (DASS-21)
Normal

Mild

Moderate

Severe

Extremely severe

Normal

Mild

Moderate

Severe

Extremely severe
$1495 \quad 47.7 \%$

$237 \quad 7.6 \%$

$569 \quad 18.2 \%$

$269 \quad 8.6 \%$

$562 \quad 17.9 \%$

$1215 \quad 38.8 \%$

$396 \quad 12.6 \%$

$641 \quad 20.5 \%$

$337 \quad 10.8 \%$

$543 \quad 17.3 \%$

$2271 \quad 75.5 \%$

$736 \quad 24.5 \%$

Notes: a Minimum salary was R\$ $1,045.00$ (corresponding to US\$ 192.17 in 04/30/2020). ${ }^{b}$ Subjective perception of the probability of financial indebtedness. ${ }^{c}$ Flu-like syndrome was considered when participants presented fever plus at least one of: cough, dyspnea, sore throat, or coryza. ${ }^{\mathrm{d}}$ Suspected COVID-19 according to a medical evaluation. Confirmed COVID-19 by laboratory tests. ${ }^{\mathrm{e}}$ Use of benzodiazepines or opioids (morphine and derivates) at least once a month, without follow-up by a doctor. ${ }^{\mathrm{f}}$ Use of cannabis, cocaine, ecstasy or LSD at least once a month. 
Table 2. Bivariate analysis of independent variables and symptoms of stress, anxiety, depression, and PTSD.

\begin{tabular}{|c|c|c|c|c|c|c|c|c|c|}
\hline & & \multicolumn{2}{|c|}{ DASS-21 Stress } & \multicolumn{2}{|c|}{ DASS-21 Anxiety } & \multicolumn{2}{|c|}{$\begin{array}{c}\text { DASS-21 } \\
\text { Depression }\end{array}$} & \multicolumn{2}{|c|}{ PCL-5 } \\
\hline & & $\begin{array}{l}M d n \\
{[I Q I]}\end{array}$ & $p$ & $\begin{array}{l}M d n \\
{[I Q I]}\end{array}$ & $p$ & $\begin{array}{l}M d n \\
{[I Q I]}\end{array}$ & $p$ & $\begin{array}{l}M d n \\
{[I Q I]}\end{array}$ & $p$ \\
\hline \multirow[t]{2}{*}{ Sex } & Male & 14 [16] & $<0.001$ & $4[10]$ & $<0.001$ & 10 [14] & $<0.001$ & $15[24]$ & $<0.001$ \\
\hline & Female & $20[16]$ & & $8[12]$ & & $14[18]$ & & $23[27]$ & \\
\hline \multirow[t]{6}{*}{ Age } & $18-25$ & $22[16]$ & $<0.001$ & $10[14]$ & $<0.001$ & $18[20]$ & $<0.001$ & $28[27]$ & $<0.001$ \\
\hline & $25-35$ & $18[16]$ & & $8[14]$ & & $12[16]$ & & 21 [27] & \\
\hline & $36-45$ & $16[12]$ & & $6[12]$ & & $10[14]$ & & 18 [26] & \\
\hline & $46-55$ & $12[12]$ & & $4[10]$ & & $8[12]$ & & $13[22]$ & \\
\hline & $56-65$ & $10[10]$ & & $2[8]$ & & $8[12]$ & & 10 [17] & \\
\hline & $66-80$ & $8[10]$ & & $4[10]$ & & $4[10]$ & & $9[17]$ & \\
\hline \multirow[t]{4}{*}{ Level of education } & Primary or secondary & 20 [18] & $<0.001$ & $10[16]$ & $<0.001$ & $16[18]$ & $<0.001$ & 28 [27] & $<0.001$ \\
\hline & Undergraduate & $22[18]$ & & $10[16]$ & & $16[20]$ & & 27 [29] & \\
\hline & Graduated & $16[14]$ & & $8[12]$ & & 12 [17] & & $20[26]$ & \\
\hline & Post-graduated & $14[14]$ & & $6[10]$ & & $10[12]$ & & $16[21]$ & \\
\hline \multirow[t]{2}{*}{ Ethnicity } & White & $18[16]$ & $<0.001$ & $8[14]$ & $<0.001$ & $12[16]$ & $<0.001$ & $21[27]$ & $<0.001$ \\
\hline & Non-white & $20[18]$ & & $10[14]$ & & $16[18]$ & & $27[28]$ & \\
\hline Marital status & Single, divorced or widowed & $20[16]$ & $<0.001$ & $8[14]$ & $<0.001$ & $14[16]$ & $<0.001$ & $25[27]$ & $<0.001$ \\
\hline & $\begin{array}{l}\text { Married or stable } \\
\text { relationship }\end{array}$ & $14[14]$ & & $6[10]$ & & $8[14]$ & & $16[25]$ & \\
\hline Occupation & Health worker & 14 [14] & $<0.001$ & $6[12]$ & $<0.001$ & $8[12]$ & $<0.001$ & $16[23]$ & $<0.001$ \\
\hline & Worker & $16[16]$ & & $6[12]$ & & $10[16]$ & & $19[25]$ & \\
\hline & Student & $22[16]$ & & $10[14]$ & & $16[20]$ & & 27 [27] & \\
\hline & Unemployed & $20[16]$ & & $10[14]$ & & $16[20]$ & & $29[31]$ & \\
\hline & Retired & $10[14]$ & & $4[10]$ & & $8[14]$ & & $10[27]$ & \\
\hline Family income (minimum & 1 or less & $24[16]$ & $<0.001$ & $14[18]$ & $<0.001$ & $20[20]$ & $<0.001$ & $33[27]$ & $<0.001$ \\
\hline salaries) & 1 to 2 & $22[16]$ & & $12[16]$ & & $18[20]$ & & $31[29]$ & \\
\hline & 2 to 8 & $18[16]$ & & $8[14]$ & & $14[16]$ & & 23 [27] & \\
\hline & 8 to 11 & $16[16]$ & & $6[12]$ & & 10 [14] & & 19 [24] & \\
\hline & 11 or more & $14[16]$ & & $4[10]$ & & $8[13]$ & & $14[20]$ & \\
\hline Financial indebtedness & Improbable & $14[16]$ & $<0.001$ & $6[10]$ & $<0.001$ & $10[16]$ & $<0.001$ & $17[23]$ & $<0.001$ \\
\hline & Possible & $18[16]$ & & $8[14]$ & & $12[16]$ & & $22[26]$ & \\
\hline & Highly probable & $20[16]$ & & $10[14]$ & & $16[18]$ & & $28[31]$ & \\
\hline & Already in debt & $22[18]$ & & 12 [16] & & $20[20]$ & & 32 [33] & \\
\hline Social distancing & No & 14 [14] & $<0.001$ & $6[10]$ & $<0.001$ & $8[14]$ & $<0.001$ & 17 [25] & $<0.001$ \\
\hline & Yes, alone & 16 [14] & & $6[14]$ & & 14 [17] & & 21 [29] & \\
\hline & Yes, accompanied & $18[16]$ & & $8[14]$ & & $14[18]$ & & $22[27]$ & \\
\hline & No & $18[16]$ & 0.004 & $8[12]$ & $<0.001$ & $12[16]$ & 0.009 & $21[26]$ & 0.001 \\
\hline Clinical diagnosis of risk & Yes & $18[18]$ & & $10[16]$ & & $14[18]$ & & $23[30]$ & \\
\hline Flu-like syndrome & No & $18[16]$ & 0.0814 & $8[14]$ & 0.005 & $12[16]$ & 0.008 & 21 [27] & 0.087 \\
\hline & Yes & $20[18]$ & & $14[18]$ & & $18[20]$ & & $26[35]$ & \\
\hline Suspected or confirmed & No & $18[16]$ & 0.956 & $8[14]$ & 0.779 & $12[16]$ & 0.518 & $21[27]$ & 0.927 \\
\hline COVID-19 & Yes & $17[13]$ & & $10[14]$ & & $12[16]$ & & $21[22]$ & \\
\hline & No & $18[16]$ & 0.010 & $8[14]$ & 0.001 & $12[16]$ & 0.047 & $21[27]$ & 0.005 \\
\hline COVID-related trauma & Yes & $20[16]$ & & $10[16]$ & & $14[14]$ & & $26[27]$ & \\
\hline Intensity of media & Mild & $16[14]$ & $<0.001$ & $6[10]$ & $<0.001$ & $10[18]$ & $<0.001$ & 15 [24] & $<0.001$ \\
\hline exposure & Moderate & $16[14]$ & & $6[12]$ & & $10[16]$ & & 20 [25] & \\
\hline & Constant & $18[16]$ & & $8[14]$ & & $12[16]$ & & $22[26]$ & \\
\hline & Extreme & $20[18]$ & & $10[14]$ & & $16[20]$ & & $26[31]$ & \\
\hline & No & $16[14]$ & $<0.001$ & $6[12]$ & $<0.001$ & $10[16]$ & $<0.001$ & 19 [25] & $<0.001$ \\
\hline Emotional abuse/violence & Yes & $26[14]$ & & $14[16]$ & & $22[20]$ & & $36[27]$ & \\
\hline Previous psychiatric & No & $16[18]$ & $<0.001$ & $6[12]$ & $<0.001$ & 10 [18] & $<0.001$ & 19 [27] & $<0.001$ \\
\hline diagnosis & Yes & $20[14]$ & & $10[14]$ & & $14[18]$ & & $25[26]$ & \\
\hline Current psychiatric & No & $14[14]$ & $<0.001$ & $5[10]$ & $<0.001$ & 10 [12] & $<0.001$ & 16 [22] & $<0.001$ \\
\hline diagnosis & Yes & $24[16]$ & & $14[14]$ & & $20[18]$ & & 34 [27] & \\
\hline Mental health treatment & No & $16[16]$ & $<0.001$ & $6[12]$ & $<0.001$ & 10 [16] & $<0.001$ & 19 [25] & $<0.001$ \\
\hline & Maintained during pandemic & 20 [14] & & $10[14]$ & & 14 [18] & & $26[26]$ & \\
\hline & Interrupted during pandemic & $22[16]$ & & $12[16]$ & & $18[18]$ & & $29[30]$ & \\
\hline Sleep duration & $>8$ hours & $20[16]$ & $<0.001$ & $8[16]$ & $<0.001$ & $16[20]$ & $<0.001$ & $25[28]$ & $<0.001$ \\
\hline & 6 to 8 hours & $16[16]$ & & $6[12]$ & & $10[14]$ & & $18[25]$ & \\
\hline & $<6$ hours & $24[14]$ & & $14[16]$ & & $16[20]$ & & $32[30]$ & \\
\hline Sleep latency & $<20$ minutes & $12[14]$ & $<0.001$ & $4[10]$ & $<0.001$ & $8[14]$ & $<0.001$ & $13[20]$ & $<0.001$ \\
\hline & 20 to 30 minutes & $16[12]$ & & $6[10]$ & & $10[14]$ & & $19[23]$ & \\
\hline & 30 to 60 minutes & $20[16]$ & & $10[14]$ & & $14[16]$ & & $26[25]$ & \\
\hline & $>60$ minutes & $26[14]$ & & $14[16]$ & & $20[20]$ & & 37 [29] & \\
\hline Use of tobacco & No & $18[16]$ & 0.700 & $8[14]$ & 0.344 & $12[16]$ & 0.011 & $21[27]$ & 0.020 \\
\hline & Yes & $18[20]$ & & $8[16]$ & & $16[20]$ & & $25[32]$ & \\
\hline Use of benzodiazepines & No & $16[16]$ & $<0.001$ & $8[12]$ & $<0.001$ & $12[18]$ & $<0.001$ & $21[27]$ & $<0.001$ \\
\hline & Yes & $24[14]$ & & 12 [14] & & $18[20]$ & & $31[28]$ & \\
\hline Use of opioids & No & $18[16]$ & 0.003 & $8[14]$ & $<0.001$ & $12[16]$ & 0.003 & $21[27]$ & $<0.001$ \\
\hline & Yes & $20[16]$ & & $12[14]$ & & $16[20]$ & & 28 [29] & \\
\hline Use of cannabis & No & $16[16]$ & $<0.001$ & $6[12]$ & $<0.001$ & $12[18]$ & $<0.001$ & $20[27]$ & $<0.001$ \\
\hline & Yes & $22[16]$ & & $12[14]$ & & $18[18]$ & & $28[27]$ & \\
\hline Use of cocaine, ecstasy, & No & 18 [16] & 0.001 & $8[14]$ & 0.006 & 12 [16] & $<0.001$ & 21 [27] & $<0.001$ \\
\hline or LSD & Yes & $22[16]$ & & $10[16]$ & & $16[20]$ & & $30[31]$ & \\
\hline
\end{tabular}


medRxiv preprint doi: https://doi.org/10.1101/2021.08.18.21262061; this version posted August 24, 2021. The copyright holder for this preprint (which was not certified by peer review) is the author/funder, who has granted medRxiv a license to display the preprint in perpetuity.

\section{It is made available under a CC-BY-NC-ND 4.0 International license .}

Table 3. Hierarchical multiple linear regression model statistics.

\begin{tabular}{|c|c|c|c|c|c|c|c|c|}
\hline Outcome & Model & Block & Adjusted $R^{2}$ & $\Delta R^{2}$ & $F$ change & $f d 1$ & $f d 2$ & $p$ \\
\hline \multirow[t]{5}{*}{ DASS-21 Stress } & 1 & Age, sex, and education & 0.159 & 0.160 & 187.908 & 3 & 2966 & $<0.001$ \\
\hline & 2 & Socioeconomic factors & 0.192 & 0.035 & 16.088 & 8 & 2958 & $<0.001$ \\
\hline & 3 & COVID-related variables & 0.422 & 0.231 & 148.495 & 8 & 2950 & $<0.001$ \\
\hline & 4 & Psychiatric characteristics & 0.499 & 0.078 & 65.851 & 7 & 2943 & $<0.001$ \\
\hline & 5 & Substance use & 0.503 & 0.005 & 4.667 & 6 & 2937 & $<0.001$ \\
\hline \multirow[t]{5}{*}{ DASS-21 Anxiety } & 1 & Age, sex, and education & 0.122 & 0.123 & 138.175 & 3 & 2963 & $<0.001$ \\
\hline & 2 & Socioeconomic factors & 0.165 & 0.046 & 20.265 & 8 & 2955 & $<0.001$ \\
\hline & 3 & COVID-related variables & 0.356 & 0.191 & 110.169 & 8 & 2947 & $<0.001$ \\
\hline & 4 & Psychiatric characteristics & 0.452 & 0.097 & 75.240 & 7 & 2940 & $<0.001$ \\
\hline & 5 & Substance use & 0.454 & 0.003 & 2.552 & 6 & 2934 & 0.018 \\
\hline \multirow[t]{5}{*}{ DASS-21 Depression } & 1 & Age, sex, and education & 0.120 & 0.121 & 136.115 & 3 & 2967 & $<0.001$ \\
\hline & 2 & Socioeconomic factors & 0.176 & 0.058 & 25.959 & 8 & 2959 & $<0.001$ \\
\hline & 3 & COVID-related variables & 0.347 & 0.173 & 98.227 & 8 & 2951 & $<0.001$ \\
\hline & 4 & Psychiatric characteristics & 0.428 & 0.082 & 60.785 & 7 & 2944 & $<0.001$ \\
\hline & 5 & Substance use & 0.435 & 0.007 & 6.464 & 6 & 2938 & $<0.001$ \\
\hline \multirow[t]{5}{*}{ PCL-5 } & 1 & Age, sex, and education & 0.111 & 0.112 & 120.044 & 3 & 2851 & $<0.001$ \\
\hline & 2 & Socioeconomic factors & 0.177 & 0.068 & 29.555 & 8 & 2843 & $<0.001$ \\
\hline & 3 & COVID-related variables & 0.372 & 0.196 & 111.603 & 8 & 2835 & $<0.001$ \\
\hline & 4 & Psychiatric characteristics & 0.473 & 0.101 & 78.355 & 7 & 2828 & $<0.001$ \\
\hline & 5 & Substance use & 0.477 & 0.005 & 4.284 & 6 & 2822 & $<0.001$ \\
\hline
\end{tabular}

Notes. DASS-21: Depression, Anxiety and Stress Scale. PCL-5: Posttraumatic Checklist for DSM-5. Statistically significant $p$-values are highlighted in bold. $R^{2}$ represents the percentage of the outcome variable explained by the model. $\Delta R^{2}$ means the amount of improve in the prediction of the outcome when a new block of variables is added to the model. $F$ statistic indicates the ANOVA statistic for the model. $f d::$ freedom degrees. 
Table 4 - Hierarchical multiple linear regression coefficients for DASS-21 Stress, Anxiety, and Depression, and PCL-5 scores.

\begin{tabular}{|c|c|c|c|c|c|c|c|c|}
\hline & \multicolumn{2}{|c|}{ DASS-21 Stress } & \multicolumn{2}{|c|}{ DASS-21 Anxiety } & \multicolumn{2}{|c|}{$\begin{array}{c}\text { DASS-21 } \\
\text { Depression }\end{array}$} & \multicolumn{2}{|c|}{ PCL-5 } \\
\hline & $\beta$ & $p$ & $\beta$ & $p$ & $\beta$ & $p$ & $\beta$ & $p$ \\
\hline Age & -0.245 & $<0.001$ & -0.184 & $<0.001$ & -0.181 & $<0.001$ & -0.163 & $<0.001$ \\
\hline Female (vs. male) & 0.094 & $<0.001$ & 0.075 & $<0.001$ & 0.022 & 0.140 & 0.047 & 0.001 \\
\hline Level of education & -0.015 & 0.357 & -0.072 & $<0.001$ & -0.014 & 0.422 & -0.028 & 0.118 \\
\hline Single, divorced, or widowed (vs. married) & 0.016 & 0.334 & 0.007 & 0.682 & -0.015 & 0.379 & -0.004 & 0.833 \\
\hline Non-white ethnicity (vs. white) & 0.011 & 0.429 & 0.014 & 0.322 & 0.011 & 0.449 & 0.017 & 0.224 \\
\hline Occupation - health worker ${ }^{\mathrm{a}}$ & 0.001 & 0.921 & 0.007 & 0.657 & -0.024 & 0.129 & -0.024 & 0.126 \\
\hline Occupation- student $^{\mathrm{a}}$ & 0.041 & 0.033 & -0.026 & 0.197 & 0.050 & 0.014 & 0.031 & 0.116 \\
\hline Occupation - unemployed ${ }^{\mathrm{a}}$ & -0.008 & 0.592 & -0.008 & 0.570 & 0.032 & 0.031 & 0.020 & 0.170 \\
\hline Occupation - retiree ${ }^{\mathrm{a}}$ & 0.018 & 0.236 & 0.037 & 0.021 & 0.034 & 0.035 & 0.032 & 0.046 \\
\hline Family income & -0.019 & 0.211 & -0.076 & $<0.001$ & -0.051 & 0.002 & -0.063 & $<0.001$ \\
\hline Financial indebtedness & 0.055 & $<0.001$ & 0.037 & 0.011 & 0.074 & $<0.001$ & 0.093 & $<0.001$ \\
\hline Social distancing - alone & 0.037 & 0.030 & 0.030 & 0.097 & 0.092 & $<0.001$ & 0.057 & 0.002 \\
\hline Social distancing - accompanied & 0.047 & 0.006 & 0.041 & 0.025 & 0.059 & 0.002 & 0.043 & 0.019 \\
\hline Frequency of exposure to news of pandemic & 0.036 & 0.007 & 0.028 & 0.045 & 0.047 & 0.001 & 0.057 & $<0.001$ \\
\hline Intensity of distress related with news of pandemic & 0.352 & $<0.001$ & 0.301 & $<0.001$ & 0.259 & $<0.001$ & 0.272 & $<0.001$ \\
\hline Clinical comorbidity of risk for COVID-19 & 0.036 & 0.007 & 0.052 & $<0.001$ & 0.019 & 0.189 & 0.028 & 0.045 \\
\hline Flu-like syndrome & 0.001 & 0.961 & 0.027 & 0.050 & 0.025 & 0.075 & 0.008 & 0.542 \\
\hline COVID-related trauma & 0.005 & 0.690 & 0.028 & 0.047 & -0.004 & 0.765 & 0.007 & 0.630 \\
\hline Emotional abuse/violence & 0.115 & $<0.001$ & 0.081 & $<0.001$ & 0.132 & $<0.001$ & 0.148 & $<0.001$ \\
\hline Previous psychiatric diagnosis & 0.029 & 0.032 & 0.046 & 0.001 & 0.024 & 0.091 & 0.040 & 0.005 \\
\hline Current psychiatric diagnosis & 0.160 & $<0.001$ & 0.216 & $<0.001$ & 0.174 & $<0.001$ & 0.179 & $<0.001$ \\
\hline Maintained psychiatric treatment & 0.033 & 0.021 & -0.008 & 0.590 & 0.009 & 0.550 & 0.031 & 0.042 \\
\hline Interrupted psychiatric treatment & 0.018 & 0.204 & 0.003 & 0.822 & 0.034 & 0.027 & 0.030 & 0.048 \\
\hline Long sleep duration ${ }^{\mathrm{b}}$ & -0.019 & 0.170 & -0.015 & 0.308 & 0.081 & $<0.001$ & -0.006 & 0.661 \\
\hline Short sleep duration ${ }^{b}$ & 0.095 & $<0.001$ & 0.103 & $<0.001$ & 0.052 & 0.001 & 0.081 & $<0.001$ \\
\hline Increased sleep latency & 0.156 & $<0.001$ & 0.149 & $<0.001$ & 0.158 & $<0.001$ & 0.194 & $<0.001$ \\
\hline Use of tobacco & -0.009 & 0.511 & 0.001 & 0.958 & 0.037 & 0.012 & 0.030 & 0.037 \\
\hline Alcohol consumption (AUDIT-C) & 0.050 & 0.001 & 0.016 & 0.302 & 0.038 & 0.016 & 0.032 & 0.041 \\
\hline Use of benzodiazepines & 0.030 & 0.029 & 0.040 & 0.006 & 0.043 & 0.003 & 0.040 & 0.005 \\
\hline Use of opioids & -0.021 & 0.110 & 0.008 & 0.567 & -0.013 & 0.350 & 0.008 & 0.589 \\
\hline Use of cannabis & 0.026 & 0.090 & 0.021 & 0.192 & 0.036 & 0.031 & -0.016 & 0.336 \\
\hline Use of cocaine, ecstasy, or LSD & -0.025 & 0.086 & -0.021 & 0.181 & -0.023 & 0.145 & 0.016 & 0.296 \\
\hline
\end{tabular}

${ }^{\mathrm{a}}$ Compared with workers. ${ }^{\mathrm{b}}$ Compared with sleep duration between 6 and 8 hours.

Notes: The different background colors represent each block in the hierarchical regression. Intercepts were omitted from the table. Coefficients are standardized Bs, which mean the amount of change in the outcome variable (in standard deviations) when the predictor increases one unit (or, in case of dichotomous variables, change from no to yes, for example). Standardized $\beta$ s are used to easily compare the effect size of each predictor. Statistically significant $p$-values are highlighted in bold. 
medRxiv preprint doi: https://doi.org/10.1101/2021.08.18.21262061; this version posted August 24, 2021. The copyright holder for this preprint (which was not certified by peer review) is the author/funder, who has granted medRxiv a license to display the preprint in perpetuity.

\section{It is made available under a CC-BY-NC-ND 4.0 International license .}

Figure 1. Prevalences of self-reported prior and current psychiatric diagnoses.

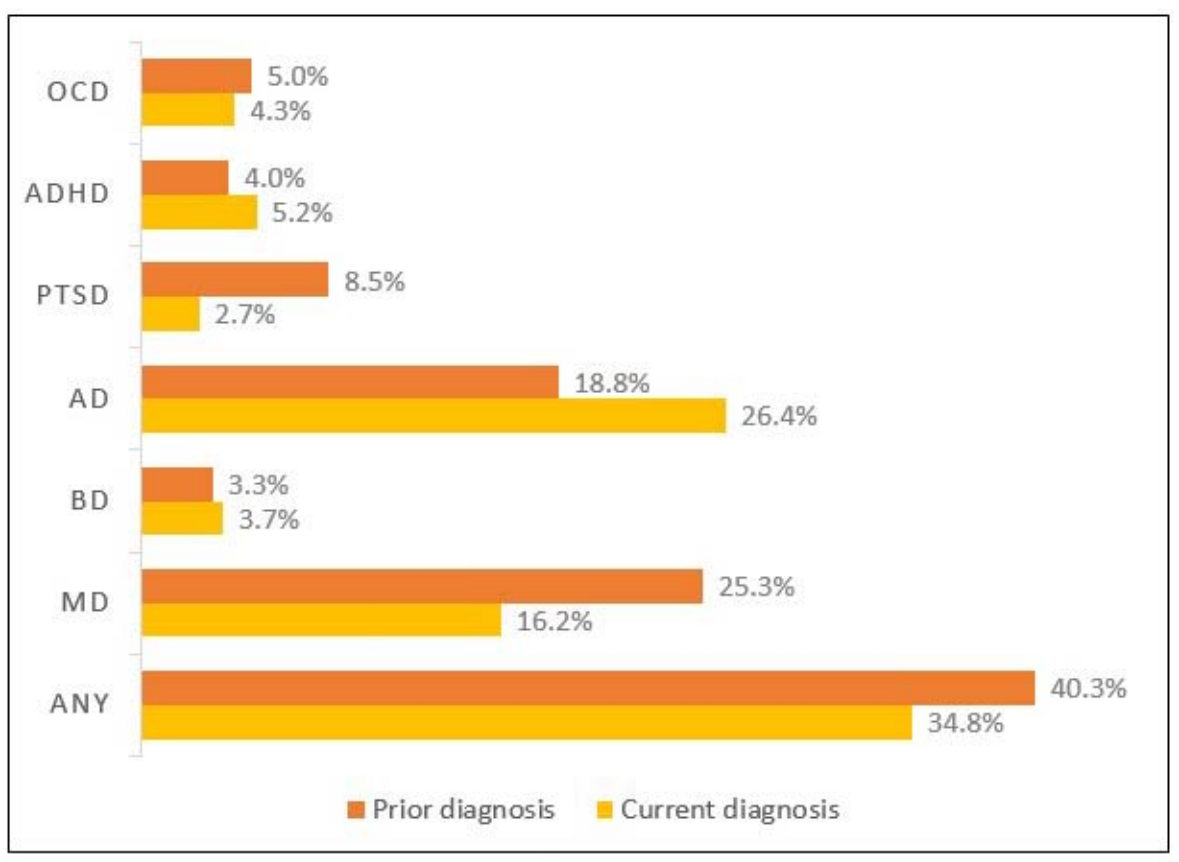

Notes. OCD: obsessive-compulsive disoreder. ADHD: Attention deficit hyperactivity disorder. PTSD: posttraumatic stress disorder. AD: anxiety disorders (generalized anxiety disorder, social anxiety disorder, panic disorder). BD: bipolar disorder. MD: major depressive disorder. 
medRxiv preprint doi: https://doi.org/10.1101/2021.08.18.21262061; this version posted August 24, 2021. The copyright holder for this preprint (which was not certified by peer review) is the author/funder, who has granted medRxiv a license to display the preprint in perpetuity.

It is made available under a CC-BY-NC-ND 4.0 International license.

Figure 2. Self-perceived change in mental health after the onset of the pandemic.

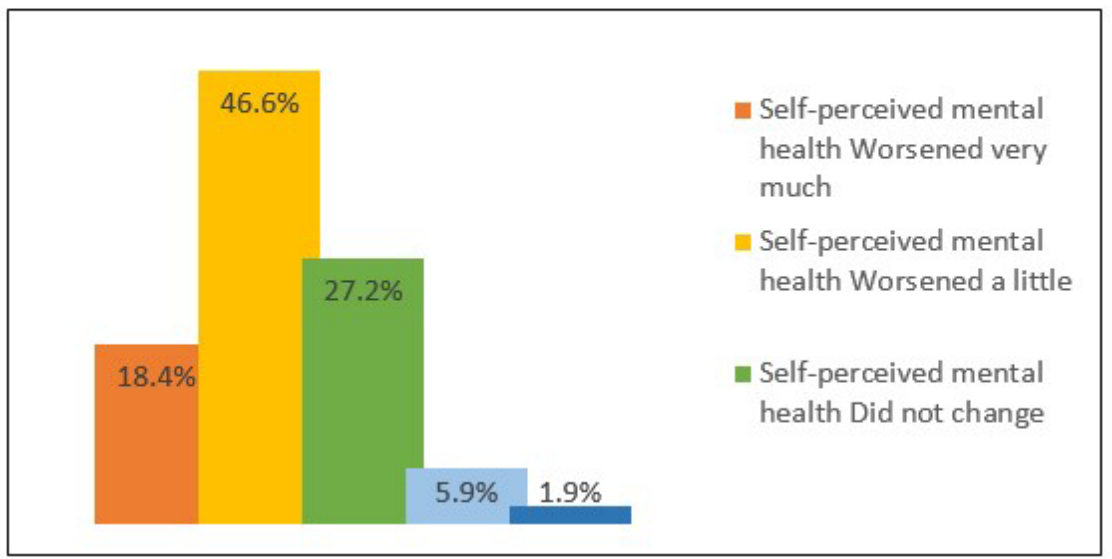


Figure 1. Prevalences of self-reported prior and current psychiatric diagnoses.

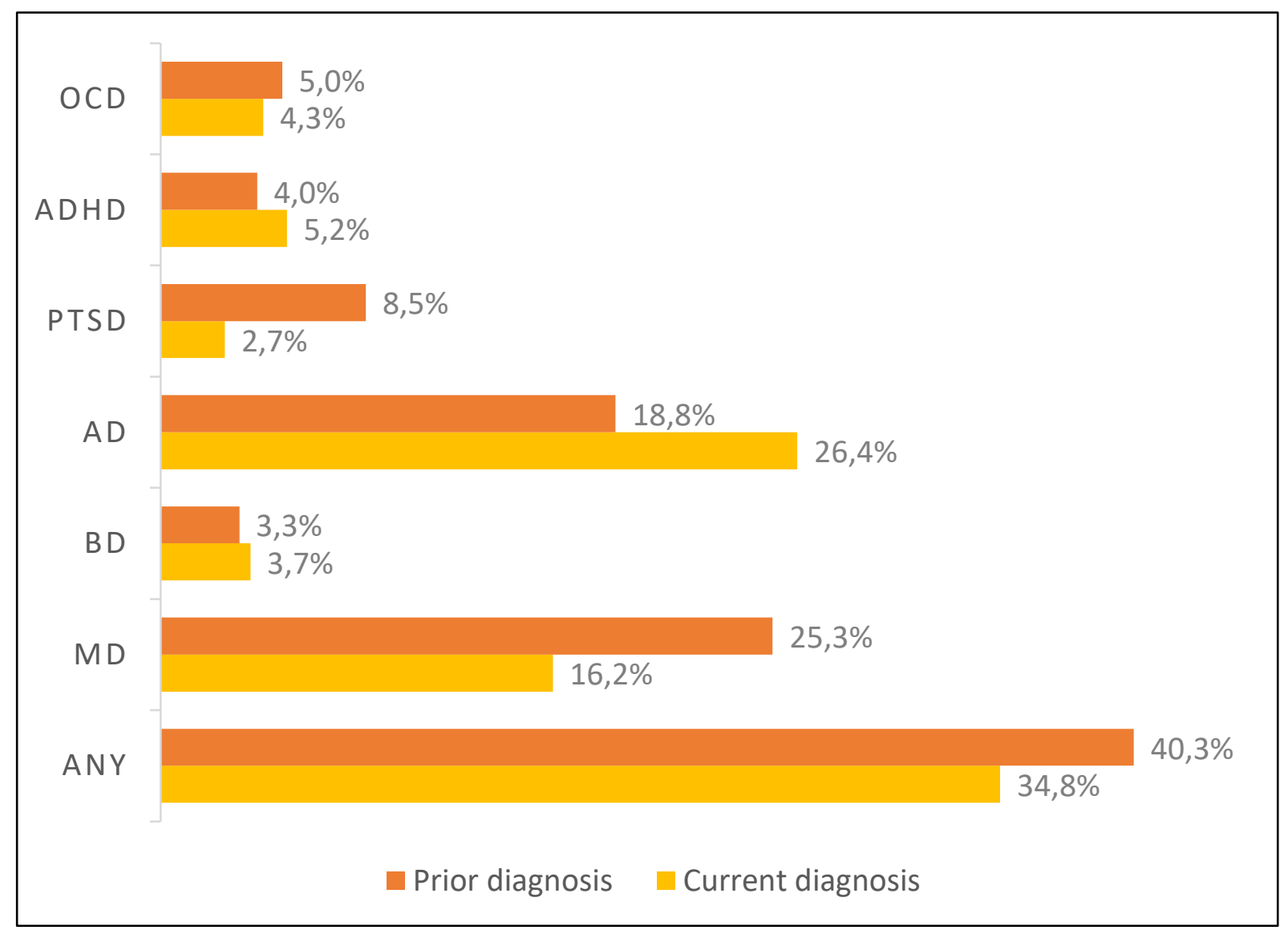

Notes. OCD: obsessive-compulsive disoreder. ADHD: Attention deficit hyperactivity disorder. PTSD: posttraumatic stress disorder. AD: anxiety disorders (generalized anxiety disorder, social anxiety disorder, panic disorder). BD: bipolar disorder. MD: major depressive disorder. 
Figure 2. Self-perceived change in mental health after the onset of the pandemic.

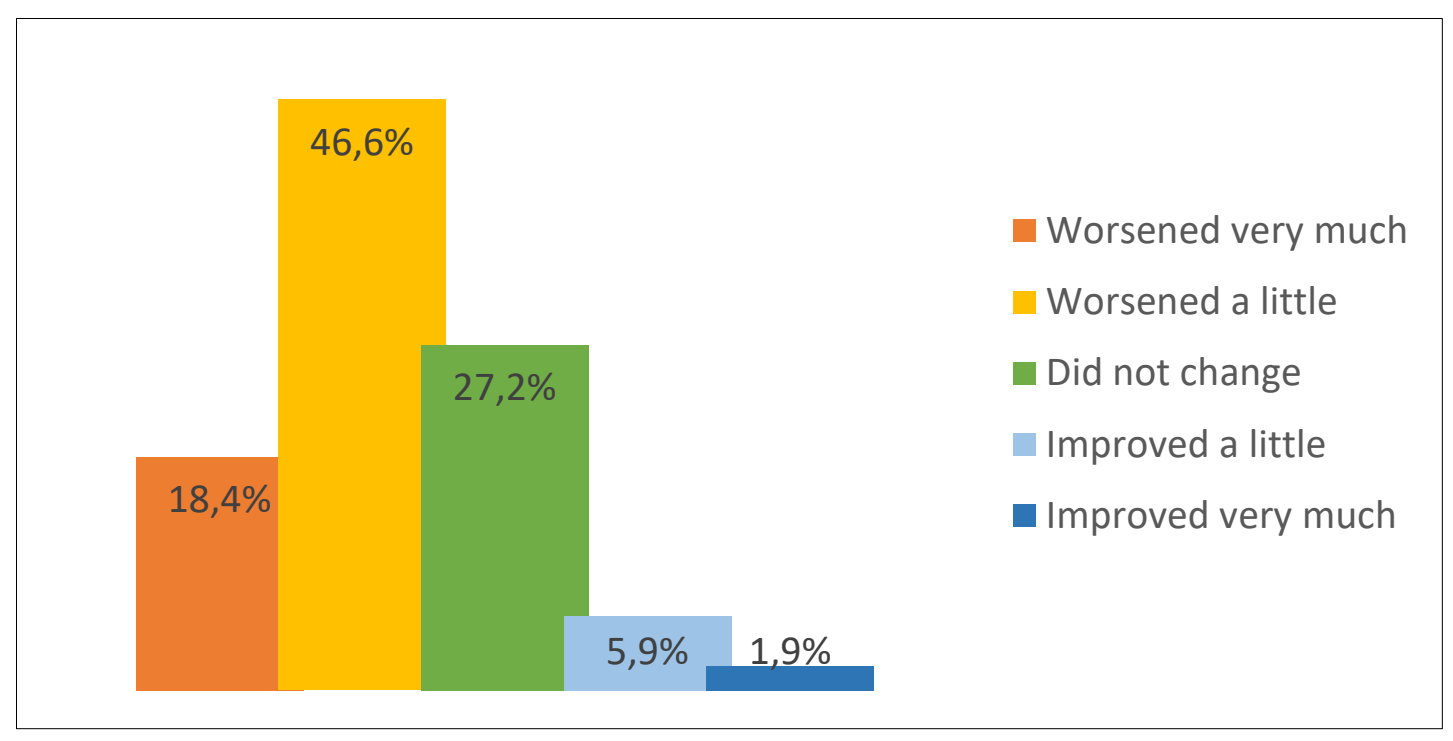

